Personalidade Acadêmica Homenageada:

Florisbal de Souza Del'Olmo (Professor Convidado - UNICURITIBA)

\title{
OS DESAFIOS DA DEFESA DOS DIREITOS DA PERSONALIDADE DIANTE DAS VIOLAÇÕES DO DIREITO DE IMAGEM E SUA RESPONSABILIDADE CIVIL NA ATUALIDADE
}

\section{LA DIFESA DEI DIRITTI DEI PERSONALITA CONTESTA FRONTE DIRITTO VIOLAZIONI E LA SUA RESPONSABILITA NOTIZIE}

\section{HORÁCIO MONTESCHIO}

Pos doutorando na Universidade de Coimbra - Portugal e pelo UNICURITIBA, Paraná - Brasil. Doutor em Direito pela Faculdade Autônoma de São Paulo- FADISP. Mestre em Direitos da Personalidade - UNICESUMAR. Professor de Direito Administrativo Administrativo e Processo Administrativo do UNICURITIBA. Pós graduado em Direito Imobiliário e Direito processual civil pela Escola Paulista de Direito. Especialista em Processo Civil e Direito Público, pelo Instituto Brasileiro de Estudos Jurídicos, Direito Tributário, pela UFSC; em Direito Administrativo, pelo Instituto Romeu Felipe Bacellar; Direito Aplicado pela Escola da Magistratura do Estado do Paraná. Advogado, exSecretário de Estado da Indústria e Comercio e Assuntos do Mercosul do Estado do Paraná, ex-Secretário Municipal para Assuntos Metropolitanos de Curitiba; Integrante do Instituto dos Advogado do Paraná (IAP). Membro fundador e integrante do Instituto Paranaense de Advogados Eleitoralistas. Integrante das comissões de Direito Eleitoral e de Assuntos Legislativos da OAB/PR. ex-conselheiro do SEBRAE. ex-Presidente do Conselho da Junta Comercial do Estado do Paraná. Membro do Conselho Editorial do Instituto Paranaense de Direito Eleitoral.

\section{CLAYTON REIS}

Doutor em Direito pela Universidade Federal do Paraná (1999). Mestre em Direito pela Universidade Federal do Paraná (1996). Bacharel em Direito pela Faculdade de Direito de Curitiba (1970). Magistrado em Segundo Grau, aposentado, do TJPR. 


\section{Personalidade Acadêmica Homenageada:}

Florisbal de Souza Del'Olmo (Professor Convidado - UNICURITIBA)

Professor na Escola da Magistratura do Paraná e pertence ao Corpo Docente Permanente do Programa de Mestrado em Direito Empresarial e Cidadania do UNICURITIBA. Realizou estágio Pós-doutoral na Faculdade de Direito da Universidade de Lisboa-Portugal (2013). Tem experiência em: Direito Civil: Responsabilidade Civil, Dano Moral. Direitos da Personalidade e Cidadania.

\section{GUSTAVO AFONSO MARTINS}

Mestre em Direito Empresarial e Cidadania pelo Centro Universitário Curitiba UNICURITIBA. Curso em Direito Internacional Público e Direitos Humanos organizado pelo lus Gentium Conimbrigae - Centro de Direitos Humanos. Universidade de Coimbra-Pt. Advogado desde 2012. Pós Graduação pela Ematra Escola da Magistratura do Trabalho - 9a Região (2014); Pós Graduação pela Faculdade Integrada do Brasil - Unibrasil (2012) em Direito Público; Possui graduação em Direito pela Faculdade Dom Bosco - Campus Marumby (2011). E-mail: gustavoamartins.cwb@gmail.com

\section{RESUMO}

A vida em sociedade tem suscitado, no âmbito jurídico, uma série de discussões e, por sua vez, uma nova avaliação por parte do Poder Judiciário. Os direitos da personalidade, alçados a patamar constitucional pela Constituição Federal de 1988, entre os quais expressamente acabou por conferir destaque ao direito de imagem e sua respectiva proteção. Com as inovações tecnológicas de comunicação de massa, bem como a sua democratização para aquisição e uso destes dispositivos, por via de consequência, a exposição pessoal ou mesmo a possibilidade de exposição de imagens pessoais ou mesmo íntimas, trazem ao lume uma nova situação de violação de direitos da personalidade, nos quais, a responsabilidade civil pecuniária deve ser fixada em valores compatíveis com a violação sofrida.

Os direitos de personalidade, no Brasil, somente foram efetivamente reconhecidos com a promulgação da Constituição Federal de 5 de outubro de 1988, 


\section{Personalidade Acadêmica Homenageada:}

Florisbal de Souza Del'Olmo (Professor Convidado - UNICURITIBA)

de forma a consagrar a cláusula genérica da dignidade da pessoa humana em seu art. 1ㅜ, inc. III. Posteriormente, com a entrada em vigor do Código Civil brasileiro, Lei no 10.406/02, os direitos da personalidade receberam tratamento que não havia sido concedido no Código de 1916.

A justificativa para ausência no Código Civil de 1916, entre os seus comandos normativos, reside no fato de quando da sua concepção, no sistema legal pátrio, preponderava à proteção do patrimônio privado, em razão da forte influência do liberalismo que norteou a sua elaboração.

Por sua vez, cabe ressaltar que mundialmente a elaboração legislativa, para a proteção dos direitos da personalidade somente é verificada após os horrores da II Guerra Mundial, a exemplo da Declaração Universal dos Direitos humanos de 1948.

No caso específico do presente trabalho, voltado para a proteção dos direitos da personalidade, entre eles os direitos relacionados à imagem e sua responsabilidade civil, inicialmente, cabe destacar que esses direitos, foram reconhecidos como fundamentais, no inc. $X$ do art. 5 da Constituição Federal.

Acompanhando a evolução legislativa presente na Constituição Federal o Código Civil de 2002, veio a disciplinar o direito de imagem em seu art. 20. Fiel à delimitação do tema, no mesmo Código, as questões relativas à responsabilidade civil foram alvo de disciplina nos arts. 186 e 927, sendo que este último dispositivo veio a consagrar a responsabilidade civil objetiva, a qual, a seguir será a norteadora das decisões relacionadas à utilização indevida na imagem.

Ademais, a temática envolvendo o direito de imagem e sua respectiva responsabilidade civil, inclusive pela perda de uma chance, bem como pela lesão a moral do seu titular, se encontram em congruência de tutela com as súmulas 37,227 e 403 do Superior 119 Tribunal de Justiça, e nos Enunciados 406, 446, 454 e 553 formulados nas I, III, IV e V das Jornadas de Direito Civil do Conselho da Justiça Federal.

Diante deste arcabouço legislativo, cujo suporte fático é indelével e de importância singular em nossa sociedade, o qual veio a estabelecer um regramento disciplinador sobre o direito de imagem e sua responsabilidade civil. Aliando-se a estes, as Súmulas e Enunciados foram elaborados, os quais são objeto de 


\section{Personalidade Acadêmica Homenageada:}

Florisbal de Souza Del'Olmo (Professor Convidado - UNICURITIBA)

ponderação neste trabalho e, o seu conteúdo programático, ressaltado delimitandose o se espectro de abrangência a recomposição do patrimônio lesado na justa medida da agressão sofrida.

\section{CONSIDERAÇÕES}

Em razão do acima exposto, formula-se a conclusão do presente trabalho, com a fixação de pontos que são fundamentais à defesa dos direitos da personalidade, os quais quando violados deve ser reparados de forma a ressarcir a dor sofrida por aquele que teve seu direito fundamental violado e, que a condenação, pecuniária ou não, venha a servir de paradigma para que o violador não venha a praticá-lo novamente.

Há que se destacar o fato de que a imagem pessoa, quando violada, dificilmente será recomposta em sua integralidade, razão pela qual ao formular o pedido de tutela judicial o autor deverá estabelecer o alcance fático da violação, a capacidade financeira do violador, descrever que não se trata de caso de busca de um "enriquecimento indevido" pela dor sofrida ou até mesmo pela ocorrência da responsabilização civil por perda de uma chance. Se mesmo assim não houver possibilidade de estabelecer parâmetros seguros para uma decisão, singular para o caso concreto, deverá o julgador designar audiência para dirimir as possíveis dúvidas com fundamento no Enunciado 454 da Justiça Federal.

Por seu turno, em razão da complexidade da realidade vivida na era da comunicação digital instantânea, nos moldes em que a sociedade está inserida, as violações se toram cada vez mais constantes, o que passa a exigir uma postura judicial específica e particular, ao contrário da verificada atualmente, na qual há um tabelamento dos valores das condenações violadoras dos direitos da personalidade.

Destarte esse desafio de rever as violações dos direitos da personalidade, no caso concreto, deve ser feito de forma a consagrar uma postura fundamentadora do pedido, fixado sua extensão, bem como do Poder Judiciário em analisar, individualmente o caso concreto, e impor condenação financeira ou, aplicar a sanção 
Personalidade Acadêmica Homenageada:

Florisbal de Souza Del'Olmo (Professor Convidado - UNICURITIBA)

pecuniária, as quais devem ficar em patamares compatíveis a descrição contida na inicial. Por derradeiro, os ideários aqui apresentados, ainda que de forma resumida, representam os desafios da defesa dos direitos da personalidade em face das violações aos direitos de imagem.

\section{REFERÊNCIAS}

ARAUJO, Luiz Alberto David. A proteção constitucional da própria imagem. São Paulo: Verbatim, 2013.

BÍBLIA SAGRADA. Trad. Do Padre Antonio Pereira de Figueiredo. Rio de Janeiro : Barsa, 1965.

CAVALIERI FILHO, Sergio. Programa de responsabilidade civil. São Paulo : Atlas, 2009.

CHAVES, Antonio. Direito à própria imagem. São Paulo Revista dos Tribunais. v. 451.

CUPIS, Adriano de. Os direitos da personalidade. Lisboa : livraria morais, 1961.

DUARTE, Fernanda; VIEIRA, José Ribas; CAMARGO, Maria Lacombe; GOMES, Maria Paulina. (coords.) Os direitos à honra e à imagem pelo Supremo Tribunal Federal : Laboratório de análise jurisprudencial. Rio de Janeiro : Renovar, 2006.

DUVAL, Hermano. Direito à imagem. São Paulo : Saraiva. 1988.

FACHIN, Zulmar Antônio. A proteção jurídica da imagem. São Paulo: Celso Bastos, 1999.

FERRARA, Francesco. Trattato di diritto civile italiano. Roma: Atheneum, 1921. 135

FESTAS, David de Oliveira. Do conteúdo patrimonial do direito à imagem. Coimbra: Coimbra, 2009.

GARCIA, Enéas Costa. Direito geral da personalidade no sistema jurídico brasileiro. São Paulo: Juarez de Oliveira, 2007.

HEINZMANN, Clara. O princípio da dignidade da pessoa humana direito de imagem - dano moral. In: Responsabilidade civil em face da violação aos direitos da personalidade: uma pesquisa multidisciplinar. REIS, Clayton (coord.). Curitiba: Juruá, 2011. 
Personalidade Acadêmica Homenageada:

Florisbal de Souza Del'Olmo (Professor Convidado - UNICURITIBA)

JABUR, Gilberto Haddad. Liberdade de pensamento e direito à vida privada: conflitos entre direitos da personalidade. São Paulo Revista dos tribunais. 2000.

LIMA, Arnaldo Siqueira de. 0 direito à imagem: proteção jurídica e limites de violação. Brasília: Universa, 2003.

NERY JUNIOR, Nelson; NERY, Rosa Maria de Andrade. Constituição federal comentada e legislação constitucional. São Paulo: Revista dos Tribunais, 2012.

NEVES, Allessandra Helena. Direito de autor e direito à imagem: à luz da constituição federal e do código civil. Curitiba: Juruá, 2011.

NUNES, Luiz Antonio Rizzato. Comentários ao código de defesa do consumidor: direito material. São Paulo : Saraiva, 2000.

REIS, Clayton. A teoria do risco na modernidade - uma antevisão do futuro. In:

Responsabilidade civil. LEITE, Eduardo de Oliveira (coord.) Rio de Janeiro : Forense, 2006.

ROSENVALD, Nelson. As funções da responsabilidade civil : a reparação e a pena civil. São Paulo : Atlas, 2014.

SAHM, Regina. Direito à imagem no direito civil contemporâneo : de acordo com o novo código civil, Lei no 10.406, de 10-1-2002. São Paulo :a atlas, 2002.

SCHREIBER, Anderson. Direitos da personalidade. São Paulo : Atlas, 2001.

Novos paradigmas da responsabilidade civil : da erosão dos filtros da reparação à diluição dos danos. São Paulo : Atlas, 2013.

SOUSA, Rabindranath Valentino Aleixo Capelo de. 0 direito geral de personalidade. Coimbra : Coimbra, 2011.

SOUZA, Carlos Affonso Pereira de. Direito das Pessoas e dos Bens. Rio de Janeiro: FGV Direito Rio, 2010.

TARTUCE, Flávio. Os Direitos da Personalidade no novo Código Civil. 2005.

TEPEDINO, Gustavo. A tutela da personalidade no ordenamento civil-constitucional brasileiro. In: Temas de direito Civil. Rio de Janeiro : Renovar, 2001.

TOBEÑAS, José Castan. Los derechos de la personalidad. Madrid : Instituto Editorial Reus, 1952.

TORRES Patrícia de Almeida. Direito à própria imagem. São Paulo : LTR, 1998. 